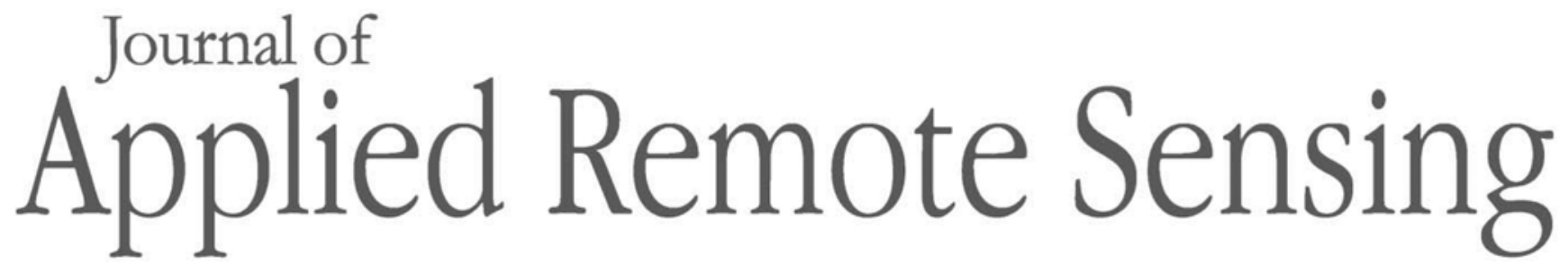

RemoteSensing.SPIEDigitalLibrary.org

\title{
Plankton Aerosol, Cloud, ocean Ecosystem mission: atmosphere measurements for air quality applications
}

\author{
Ali H. Omar \\ Maria Tzortziou \\ Odele Coddington \\ Lorraine A. Remer
}




\title{
Plankton Aerosol, Cloud, ocean Ecosystem mission: atmosphere measurements for air quality applications
}

\author{
Ali H. Omar, ${ }^{\mathrm{a}, *}$ Maria Tzortziou, ${ }^{\mathrm{b}}$ Odele Coddington, ${ }^{\mathrm{c}}$ and \\ Lorraine A. Remer ${ }^{\text {d }}$ \\ ${ }^{a}$ NASA Langley Research Center, Hampton, Virginia, United States \\ ${ }^{b}$ City College of New York, New York, United States \\ ${ }^{c}$ University of Colorado, Boulder, Colorado, United States \\ ${ }^{\mathrm{d}}$ University of Maryland Baltimore County, Baltimore, Maryland, United States
}

\begin{abstract}
We present the instrumentation and products of the NASA Plankton Aerosol, Cloud, ocean Ecosystem (PACE) mission relevant to air quality management. Since PACE will launch in the 2022 to 2023 timeframe, we discuss several activities in anticipation of a robust air quality applications program using PACE products. Products from the PACE ocean color imager and two multiangle polarimeters will be used synergistically to retrieve properties relevant to air quality applications. These instruments provide high spectral and spatial resolution measurements used to derive key properties of aerosols and clouds including effective particle radii, particle shapes, aerosol and cloud optical depths, refractive indices and single scattering albedos, all of which are critical for characterizing airmasses for managing air quality, hazardous episodes of wildfire and volcanic emissions, and long range transport of pollution. Because of the number of products with potential societal benefits, the PACE mission is highly pertinent to NASA's Applied Sciences Program's efforts to promote, discover, and demonstrate innovative, practical, and sustainable uses of the Earth observations. We discuss plans to support these efforts by establishing a prelaunch early adopter program and outline communication strategies to engage the air quality user community. () The Authors. Published by SPIE under a Creative Commons Attribution 3.0 Unported License. Distribution or reproduction of this work in whole or in part requires full attribution of the original publication, including its DOI. [DOI: 10.1117/1.JRS.12.042608]
\end{abstract}

Keywords: air quality; applications; ocean color imager; aerosol; cloud; polarimeter.

Paper 180460SS received Jun. 7, 2018; accepted for publication Aug. 24, 2018; published online Oct. 10, 2018.

\section{Introduction}

NASA's Plankton, Aerosol, Cloud, and ocean Ecosystem (PACE) mission will make global ocean color and atmospheric measurements to provide extended data records on ocean ecology and global biogeochemistry, along with polarimetry measurements to provide advanced systematic observations of aerosols and clouds. The PACE mission will monitor atmospheric processes resulting from the interaction of atmospheric gases, aerosols, and clouds with radiation. As such, applications developed using PACE observations will benefit a broad spectrum of public groups, including various local, state, federal, and international agencies, policy makers and implementers, the commercial sector, scientists, educators, and the general public. PACE atmospheric measurements will augment NASA's satellite observations of aerosols and clouds and provide a dataset that will be exploited for societal benefit applications beyond the science for which the instruments were designed. In addition, PACE atmospheric measurements will enhance methods required to correct for the effects of absorbing and scattering aerosol in the Earth's atmosphere; these signals mask or alias ocean-color retrievals that prescribe the health of the Earth's oceans.

The spatial and expanded spectral resolution, angular range and polarization measurements will be attractive to atmospheric applications data users, such as air quality practitioners and

*Address all correspondence to: Ali H. Omar, E-mail: ali.h.omar@nasa.gov 
policy makers, the renewable energy sectors, hazard warning decision makers, scientists within the federal and state governments, and those responsible for regional and global climate change prediction and mitigation. The high spectral range and resolution radiance measurements have potential applications in the retrieval of column concentrations of trace gases and solar energy availability. The insurance and reinsurance industry, policy makers, and protectors of the nation's infrastructure are concerned about the large uncertainties of estimates of climate change parameters (particularly temperature change and sea-level rise) and the local weather responses to climate change. The radiative effects of aerosols and clouds have been identified as the largest source of uncertainty in climate prediction. ${ }^{1,2}$ NASA's assets have been an essential component in ongoing research that addresses these large uncertainties due to aerosols and clouds. These same cloud and aerosol observations will be used by regulatory agencies, resource managers, and weather forecasters for applications spanning a wide range of other societal benefits. Recognizing this potential, the 2007 Decadal Survey report ${ }^{3}$ specifically poses a fundamental challenge to ensure that "societal needs help to guide scientific priorities more effectively and that emerging scientific knowledge is actively applied to obtain societal benefits." The 2017 Decadal Survey ${ }^{4}$ also affirms that "improved capacity for transitioning science to applications will make it possible to more quickly and effectively achieve the societal benefits of scientific exploration." In the report, PACE is a program of record, i.e., a previously planned observation, which will form the foundation of the next decade's observing system.

PACE atmospheric measurements will continue the heritage of aerosol measurements used to address air quality, long-range transport of pollution, and volcanic ash hazards for aviation safety. These measurements will also provide continuity in the cloud measurements record. The PACE measurements will provide new retrieval characterization information to researchers that will further reduce uncertainties in climate prediction, particularly for aerosols and augment retrievals by other NASA and NOAA satellites to provide direct benefits to society. Due to its high spectral resolution, broad spectral range and spatial coverage, and high radiometric accuracy, PACE will provide a better characterization of aerosol than can be obtained from moderate resolution imaging spectroradiometer (MODIS $)^{5}$ or ozone monitoring instrument (OMI), ${ }^{6}$ and over a broader swath than is provided by multiangle imaging spectroradiometer (MISR). ${ }^{7}$ This will lead to better assessments of the local and regional air quality and public health risk, and better characterization of hazards to aid in issuing disaster warnings for public safety, all of which will improve the ability of decision makers to manage natural resources and protect public health and property. The spectral and spatial resolution of PACE measurements will also be useful in coastal and urban areas where there are large gradients in air quality and where the air masses merge. This is particularly important as the nation sees an unprecedented growth in its coastal population. In 1999, 55\% to 60\% of Americans lived in 772 counties adjacent to the Atlantic and Pacific Oceans, the Gulf of Mexico, and the Great Lakes. By the year 2025, nearly $75 \%$ of Americans are expected to live in coastal counties. These counties already contain 14 of the country's 20 largest metropolitan areas. ${ }^{8}$ Additional PACE products that will be used to inform safety agencies, including volcanic eruption events, were identified in the PACE Science Definition Team Report. ${ }^{9}$

\section{Plankton, Aerosol, Cloud, and Ocean Ecosystem Instrument Suite}

PACE is being implemented as a NASA class $C$ mission with a notional launch date in the 2022 to 2023 timeframe and a minimum mission duration of 3 years, with orbit maintenance capabilities for 10 years. The nominal spacecraft altitude is $676.5 \mathrm{~km}$ (420 miles) with an inclination of $98 \mathrm{deg}$. The primary science instrument for PACE is the ocean color instrument (OCI) that will measure the intensity of reflected light from the ultraviolet to the shortwave infrared (i.e., 350 to $2250 \mathrm{~nm}$ ). The OCI has a ground sample distance $\leq 1 \mathrm{~km}^{2}$ at nadir with a spectral resolution of 5-nm resolution between 350 and $890 \mathrm{~nm}$, and SWIR bands centered on 940, 1038, 1250, 1380, 1615,2130 , and $2260 \mathrm{~nm}$. It has an ideal blue-red spectrograph transition range with image artifacts $<0.5 \%$ at calibrated, top of atmosphere radiances. The imager has two $2-\mu \mathrm{m}$ bands to improve retrievals of cloud thermodynamic phase, ${ }^{10}$ which are historically performed using a combination of infrared measurements along with visible and near-infrared measurements. Additional features under consideration include extending the spectral range to $\sim 315 \mathrm{~nm}$ 
Omar et al.: Plankton Aerosol, Cloud, ocean Ecosystem mission...

Table 1 Specifications of SPEXone and HARP-2.

\begin{tabular}{|c|c|c|}
\hline & HARP-2 & SPEXone \\
\hline Ground sample distance & $3 \mathrm{~km}$ & $2.5 \mathrm{~km}$ \\
\hline Spectral range [resolution] & $\begin{array}{c}440,550,670 \mathrm{~nm}[10 \mathrm{~nm}] \text { and } \\
870 \mathrm{~nm}[40 \mathrm{~nm}]\end{array}$ & $\begin{array}{l}385 \text { to } 770 \mathrm{~nm} \\
\text { [hyperspectral } 2 \mathrm{~nm} \text { ] }\end{array}$ \\
\hline $\begin{array}{l}\text { Number of viewing } \\
\text { angles [degrees] }\end{array}$ & $\begin{array}{l}20 \text { for } 440,550,870 \mathrm{~nm} \text { and } \\
60 \text { for } 670 \mathrm{~nm} \text { [spaced over } 114 \mathrm{deg}]\end{array}$ & $\begin{array}{c}5[-57 \mathrm{deg},-20 \mathrm{deg} \\
0 \mathrm{deg}, 20 \mathrm{deg}, 57 \mathrm{deg}]\end{array}$ \\
\hline Coverage [swath width] & $94 \mathrm{deg}[1550 \mathrm{~km}]$ & $9 \operatorname{deg}[100 \mathrm{~km}]$ \\
\hline Attributes & Hyperangular and wide swath & Hyperspectral and narrow swath \\
\hline
\end{tabular}

and reducing the sampling interval from 5 to $1.25 \mathrm{~nm}$ in some spectral ranges. This variable spectral super-sampling will enhance aerosol property retrievals, thereby improving atmospheric correction results. OCI will have a 2-day global coverage at 60-deg instrument view angle. PACE will also have two multiangle polarimeters (MAPs): the spectropolarimeter for planetary exploration (SPEXone) contributed by the Netherlands, and the hyper angular rainbow polarimeter (HARP-2) contributed by the University of Maryland, Baltimore County. The two polarimeters are in the microsatellites class (10 to $100 \mathrm{~kg}$ ) and will be integrated into the PACE spacecraft bus. Because the polarimeters are integrated on the spacecraft bus, the design duration of operation is longer than a free flying cubesat. Polarimeters measure the rotation of polarized light as it passes through clouds, aerosols, the upper layers of the ocean, or any optically active medium. The measured rotation can be used to retrieve the optical properties of the medium. The PACE polarimeters are very compact but differ in their spatial and spectral resolution, viewing angles, and swath width capabilities and therefore contribute complimentary capabilities for retrieving or enhancing retrievals of PACE products. HARP-2 is a hyperangular instrument with a wide swath and discrete spectral bands, whereas SPEXone is a hyperspectral instrument with a narrow swath and discrete viewing angles (Table 1).

For air quality studies, the two MAP instruments in conjunction with OCI will be exceptional for aerosol characterization. HARP-2 will provide a larger field of view for aerosol and cloud observations and, along with the hyperangular viewing, will enable retrieval of key cloud microphysical properties such as cloud droplet size, ice particle shape and roughness, and enhanced thermodynamic phase retrievals. ${ }^{11}$ The SPEXone instrument nearly completely characterizes the aerosol and cloud optical properties including the stokes $I, Q$, and $U$ parameters at multiple wavelengths and scattering angles. Table 2 shows the PACE measurement products and their potential applications. Retrievals from SPEXone will include, for aerosols: single scattering albedo, effective radius, refractive indices, aerosol optical depth, aerosol layer height, and for clouds: cloud optical thickness, effective radius, effective variance, and cloud phase, respectively.

\section{Applications of Plankton, Aerosol, Cloud, and Ocean Ecosystem Data}

Observations from the PACE mission are highly relevant to the Applied Sciences Program (ASP) within NASA's Earth Science Directorate and the programs' efforts to promote, discover, and demonstrate innovative, practical, and sustainable uses of the Earth observations. The ASP program sponsors applied science research and applications projects to enable near-term uses of the Earth observations in the nine interagency U.S. Group on Earth Observations (USGEO) Societal Benefit Areas (SBAs): agriculture, climate, disasters, ecological forecasting, energy, health, oceans, water resources, and weather. PACE atmosphere measurements are highly relevant to six of these thematic areas: health (including Air Quality), disasters, ecological forecasting, climate, ocean, and water resources. The ASP sponsored projects include formulation of new applications, integration of Earth observations and related products in practitioners' decision making, transitioning applications to operations, and developing plans for sustainability. 
Omar et al.: Plankton Aerosol, Cloud, ocean Ecosystem mission...

Table 2 Potential applications of PACE atmospheric measurements from the $\mathrm{OCI}$ and MAP.

\begin{tabular}{|c|c|c|}
\hline PACE measurement & Instrument & Application for societal benefit \\
\hline \multicolumn{3}{|l|}{ Aerosol properties } \\
\hline Aerosol optical depth & OCI/MAP & Air quality, visibility, public health \\
\hline Aerosol size distribution & OCI/MAP & Air quality, public health \\
\hline Aerosol type & OCI/MAP & Air quality, visibility \\
\hline Aerosol layer height & $\mathrm{OCl}\left(\mathrm{O}_{2} \mathrm{~A}\right.$ Band $), \mathrm{MAP}$ & $\begin{array}{l}\text { Air quality, pollution transport, } \\
\text { public health }\end{array}$ \\
\hline $\begin{array}{l}\text { Aerosol absorption from } \\
\text { UV similar to OMI }\end{array}$ & $\mathrm{OCl}$ & Air quality, public health \\
\hline \multicolumn{3}{|l|}{ Cloud properties } \\
\hline Cloud optical depth & $\mathrm{OCl}$ & Visibility, convection/precipitation \\
\hline Cloud effective particle size & OCI/MAP & Convection/precipitation \\
\hline $\begin{array}{l}\text { Effective variance of cloud } \\
\text { particle size distribution }\end{array}$ & MAP & Convection/precipitation \\
\hline Ice crystal shape & MAP & Convection/precipitation \\
\hline Cloud thermodynamic phase & OCI/MAP & Convection/precipitation \\
\hline Cloud top height/pressure & $\mathrm{OCl}\left(\mathrm{O}_{2} \mathrm{~A}\right.$ Band $)$ & Convection/precipitation \\
\hline $\begin{array}{l}\text { Trace gases-ozone, } \mathrm{NO}_{2}, \mathrm{H}_{2} \mathrm{O} \\
\text { [column measurements] }\end{array}$ & $\mathrm{OCl}$ & $\begin{array}{l}\text { Air quality, public health, humidity } \\
\text { estimates for aerosol modeling studies } \\
\text { and air quality forecasting, visibility }\end{array}$ \\
\hline Volcanic ash advisories & OCI, MAP & Disaster monitoring/warning \\
\hline Solar energy availability & OCI/MAP & Renewable energy (cloud products) \\
\hline Stratospheric aerosol concentration & (SWIR, MAP) & Climate \\
\hline Ash concentrations from Limb scattering & MAP & Disaster monitoring/warning \\
\hline $\begin{array}{l}\text { Assimilation of radiances and } \\
\text { derived products for weather forecasting }\end{array}$ & OCI/MAP & $\begin{array}{l}\text { Weather forecasting } \\
\text { (NCEP, NWS, NRL, and ECMWF) }\end{array}$ \\
\hline Imagery & $\mathrm{OCl}$ & Disaster monitoring/warning \\
\hline
\end{tabular}

The projects are carried out in partnership with public- and private-sector organizations to achieve sustained use and sustained benefits from the Earth observations. The area also addresses the effects of climate change on air quality and public health to achieve sustained use and benefits from Earth observations, ranging from the long-term effects of climate change on air quality and health, to more immediate support for public health-related decision-making. The Natural Disaster Application area uses NASA's capabilities in spaceborne, airborne, surface observations, and higher-level derived data products to improve natural disaster forecasting, mitigation, and response. Two examples, air quality and disaster monitoring using PACE measurements, are discussed next.

\section{Improving Ambient Air Quality Monitoring and Trends}

The U.S. EPA, NOAA, National Park Service (NPS), and tribal, state, and local agencies have recently developed nationwide daily air quality forecasts and near real-time reporting of air quality through the use of air quality indices (AQI, see also Ref. 12). This information is 
disseminated by the EPA through the AirNow system that produces a daily AQI from ground measurements and satellite data to advise society about how clean or polluted the air is, and its associated health effects. The high spectral and spatial resolution of PACE measurements especially in densely populated coastal regions will improve the accuracy and availability of AQI. Effective use of these products will require that the data are accessible to operational users in the right format as soon as possible.

Aerosol with aerodynamic diameters $<2.5 \mu \mathrm{m}$, commonly referred to as $\mathrm{PM}_{2.5}$ by air quality practitioners, are a federally regulated pollutant due to their deleterious effects on human health. ${ }^{13,14}$ MODIS and MISR aerosol retrievals have already been combined with groundbased monitoring network and the space-based Cloud-Aerosol Lidar and Infrared Pathfinder Satellite Observations (CALIPSO) data, as well as models to estimate $\mathrm{PM}_{2.5}$ over the continental US and globally. ${ }^{15,16} \mathrm{~A}$ common approach for estimating the $\mathrm{PM}_{2.5}$ concentrations ${ }^{17}$ at the surface involves the use of spatially and temporally resolved correction factors $(\eta)$ between ground-level $\mathrm{PM}_{2.5}$ mass concentration and satellite-retrieved column integrated AOD such that

$$
\mathrm{PM}_{2.5}=\eta \times \mathrm{AOD}, \quad \eta=\frac{\mathrm{PM}_{2.5}^{\text {model }}}{\mathrm{AOD}^{\text {model }}} .
$$

The correction factors are determined from model-derived ground-level $\mathrm{PM}_{2.5}$ mass concentration and column-integrated AOD. Continuity of these measurements using PACE and other NASA satellites will allow NASA and US policymakers to determine the effectiveness of pollution reduction initiatives. For example, PACE data could be used to extend the aforementioned MODIS and MISR $\mathrm{PM}_{2.5}$ estimates and provide insights into the decadal trends in population exposure to $\mathrm{PM}_{2.5}$ and associated health effects.

PACE measurements will also have direct applications in near-real-time monitoring of air pollution. AQI provide the public with easy access to national ambient air quality information, namely real-time and forecasted air quality conditions. Integration of future satellite data (e.g., TEMPO and PACE) with these databases will continue these forecasts, enabling public awareness of potentially deleterious air quality events that can adversely affect susceptible individuals. Figure 1 shows that, although substantial progress has been made to use satellite data to predict air quality for most of the country, a large area (shown in red) still lacks coverage. There are substantial health benefits for people who take protective action to avoid exposure to high outdoor $\mathrm{PM}_{2.5}$ concentrations. Shaded red areas in Fig. 1 are regions for which AirNow provides no air quality information, because the prediction standard error is $>\sim 5 \mu \mathrm{g} / \mathrm{m}^{3}$ (the U.S. National Ambient Air Quality $\mathrm{PM}_{2.5}$ Standard is $35 \mu \mathrm{g} / \mathrm{m}^{3}$ for $24 \mathrm{~h}$ average).

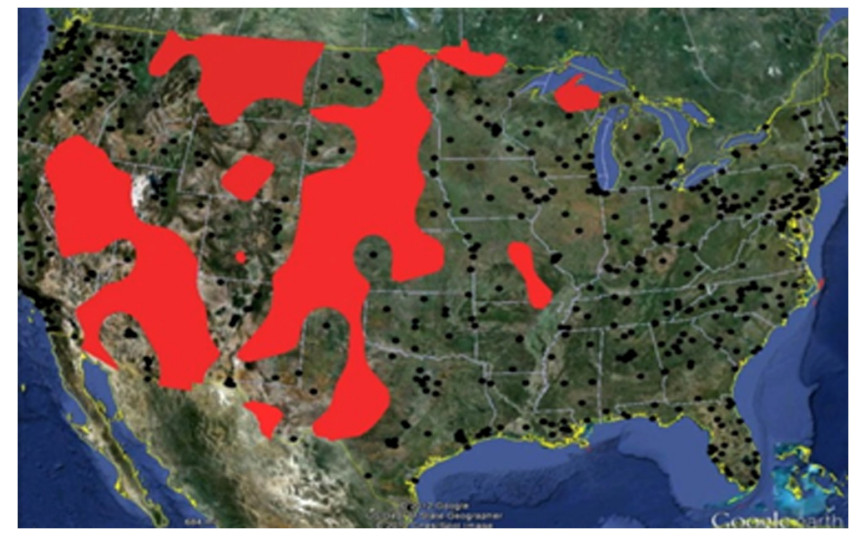

Fig. 1 AirNow surface $\mathrm{PM}_{2.5}$ observations (black dots). The red areas are gaps in the data. These results from a combination of missing ground sites and bright ground surfaces that preclude accurate retrievals of aerosol properties from satellite observations (figure courtesy of Phil Dickerson, EPA). 
Eyjafjalljokull Volcano Ash Plume - MISR Aerosol Retrieval, April 19, 2010

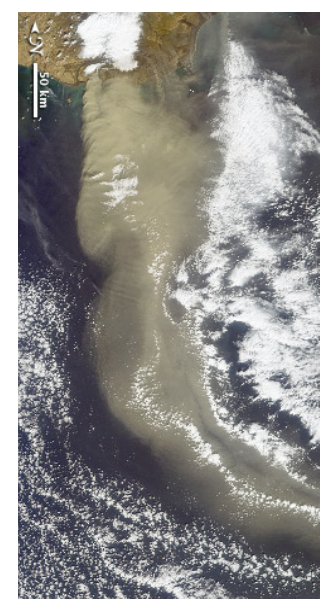

Nadir Camera Image

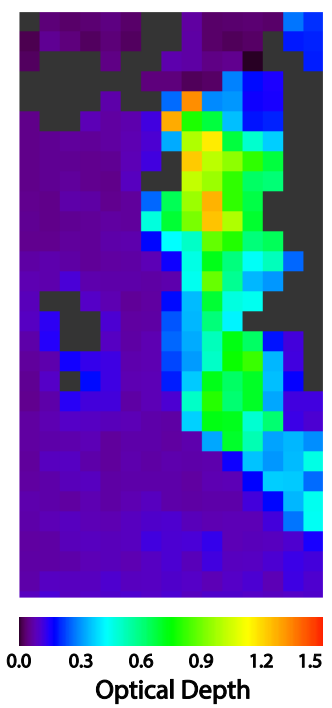

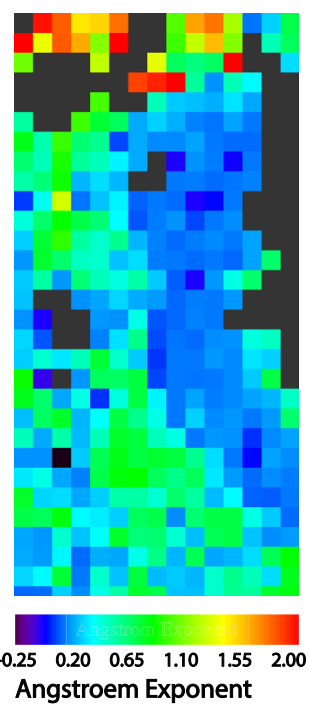

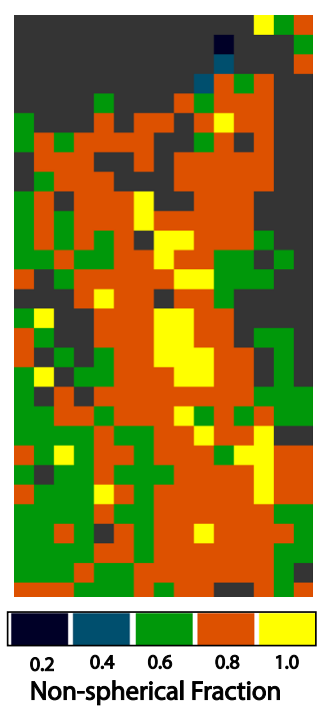

Fig. 2 An example of MISR air mass mapping applied to the Eyjafjalljökull plume on April 19, 2010. ${ }^{24}$

\section{Improving Hazard Assessment and Aviation Safety}

Aviation operations are significantly impacted by volcanic eruptions, as evident from the Eyjafjallajökull volcano in Iceland (April 2010). The Eyjafjallajökull plume was observed by many satellite sensors including OMI, MISR, MODIS, CALIPSO, and Spinning Enhanced Visible Infrared Imager (SEVIRI). ${ }^{18-23}$ Figure 2 is an image of the Eyjafjalljökull volcano ash plume plotted using MISR data retrieved on April 19, 2010.

The figure shows increasing information content moving from a camera image in the first panel to the identification of nonspherical particles (indicative of volcanic ash) in the fourth panel. Multiangle, multispectral measurements provide critical information about particle size and by inference particle type. Volcanic plumes of the $\mathrm{H}_{2} \mathrm{SO}_{4}$ particles (small water-soluble particles) are far less hazardous to aircraft than plumes consisting of ash particles (large silica based particles). Ingestion of these particles into engines causes them to melt in the combustion chamber and then to solidify on turbine blades, blocking air flow, and causing the engine to stall. So, while the small particles are relatively harmless, the large particles warrant a warning and in some cases shutting down affected airways. The PACE MAP will provide critical data for making decisions to safely manage airspace in the presence of volcanic hazards. Observations of the Eyjafjallajökull volcano in Iceland (April 2010) is a good example of how satellite data, including the OCI and MAP on PACE, can be used to provide appropriate aviation advisories with notable public safety and measurable economic benefits. Figure 2 shows MISR's airmass mapping of the Eyjafjallajökull volcano on April 19, 2010. The MISR retrieval approach is based on selecting aerosol optical models and corresponding aerosol optical depth that produce acceptable matches to the MISR-observed top of atmosphere equivalent reflectances. The hazard warning for aviation that PACE will address are the long-lived plumes of ash that form after the eruption and are sustained in a lofted state for days. The imagery and characteristics of the aged plume from the PACE OCI and polarimeters will provide information about the location and properties of the plumes to the Volcanic Ash Advisory Centers (VAACs). The VAACs disseminate information on atmospheric volcanic ash clouds that may endanger aviation. This is similar to the imagery and characteristics provided by OMI, MISR, MODIS, SEVIRI, and CALIPSO for days after the Eyjafjallajökull volcanic eruption in 2010.

\section{Engagement with Air Quality Communities}

As a new mission, PACE products must necessarily be introduced to applied practitioners and, likewise, PACE scientists must be introduced to practitioners of societal benefit applications 


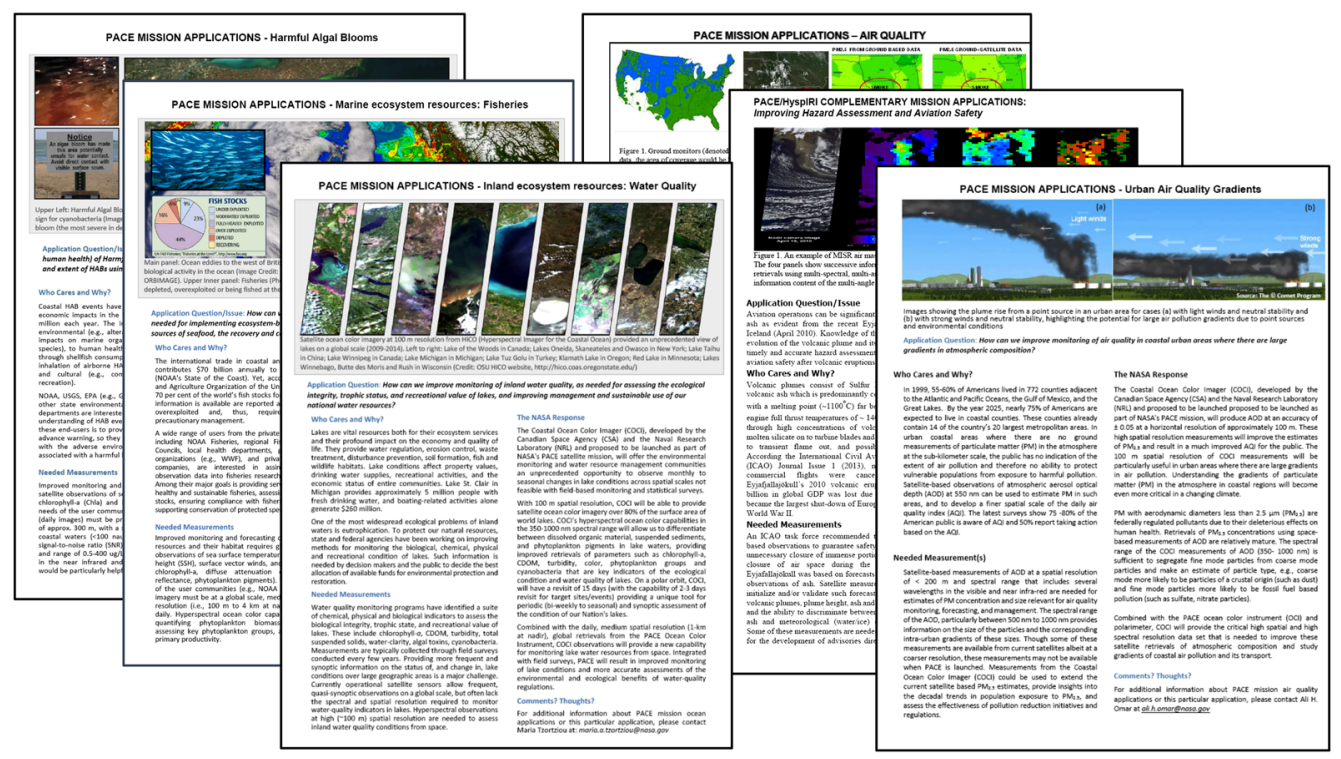

Fig. 3 Examples of one-page white papers on specific PACE applications. These one page communiques present the application question/issue, why it is important, the needed measurements and the NASA response for both atmosphere and ocean products of PACE.

because the two groups (practitioners and scientists) will need to work together to maximize the benefits of these products. The PACE mission will identify and engage potential user communities (Communities of Practice) early in the PACE mission design and development process, to ensure that the product suite and delivery mechanisms maximize the usefulness and societal value of PACE observations. Specific outreach activities, communication strategies such as the use of succinct one-page white papers shown in Fig. 3, and community engagement approaches have commenced. The objective of these communication strategies is to demonstrate the value of PACE products across a wide range of practical application areas and foster interactions between the PACE program, project team, science teams, operational users, resource managers, policy makers, and other relevant stakeholders.

Specific activities to engage users include applications workshops, tutorials, town halls, journal papers, and the popular press. The application workshops held biannually, provide feedback to the PACE mission about PACE product applications, and the thematic areas in which their products may be applied. These events provide a forum for the user groups to receive specific support and information on the utility of PACE OCI and polarimetry products. Online and offline PACE applications tutorials will be available to the early adopter (EA) to provide detailed information on a particular topic, such as introduction to specific tools and utilities for working with PACE data. Tutorials define project product application opportunities and leverage innovation for how to best combine datasets, models, and expertise for use in air quality applications. PACE science and applications organized sessions, town halls, breakout sessions in widely attended remote sensing and environmental science meetings are planned for the latter phases of the mission. Outreach materials, including PACE Applications brochures and PACE product posters will be distributed during conferences and meetings by applications and science team members throughout the life of the PACE mission.

Data workshops and short courses designed to prepare the community of practice and provide hands-on instruction on data access and use of mission data products. PACE-simulated datasets and scripts for processing and analyzing data that are customarily available to the wider science community will be disseminated at the data workshops and short courses. The PACE applications team will encourage the development of additional tools specific to the applications community by the early adopters, community of practice, science team members, and federal partners. These tools will be distributed by a suitable NASA Distributed Active Archive Center for use by the wider community. Online tools, user services, and data access will be advertized and presented to the user community during the prelaunch phase (phase D), 
so familiarity with these services will be well established by the operational phase of the mission. Articles in peer-reviewed journals and the popular press, press-releases, announcements or descriptions of the mission in newsletters, user forums, or other venues frequented by the user community will be provided to the science communications team for single point dissemination to the public. The PACE applications team will target key international user groups that are mature, have solid missions and budgets, and can ensure that investments are made in new ways of using $\mathrm{OCI} /$ polarimetry information from the PACE mission.

PACE will establish an EA program to engage the air quality community. The main goal of the EA program is to promote prelaunch applied research to facilitate feedback on PACE products prelaunch, and accelerate the use of PACE products postlaunch. PACE EAs are defined as those groups and individuals who have a direct or clearly defined need for PACE-like ocean color or polarimetry data, have an existing application or new ideas for PACE-related applications, and intend to apply their own resources to demonstrate the utility of PACE data for their particular system or model. The goal of this designation is to accelerate the use and integration of PACE products into policy, decision-making, and scientific support settings by providing specific guidance to EAs who commit to engage in prereadiness studies that incorporate PACE data in their applications. EAs will connect to the PACE project through an informal letter of interest.

In the framework of the EA program, each EA will provide an EA research project title with the end user clearly identified, and a short abstract describing the societal benefit of the project. After selection, each EA will be partnered with a science team member who can provide guidance and information on project data and product development. Through this partnership, the EA program will be beneficial to both the PACE end users and the mission, as the EAs will receive access to developmental products and interaction with the product developer enabling them to be among the first to integrate the new PACE products into their systems. The science team members will gain a partner who can evaluate products and offer feedback from a functionality perspective, as well as potential calibration and validation information. Through interactions with the PACE science and applications teams, the EAs will be able to (i) get access to and resolve issues with PACE pre-launch simulated data products and (ii) report on the EA program successes, challenges, and progress during PACE science team and applications working group meetings. An impact workshop will be held with members of the EA program and other key stakeholders and user communities at the start of flight phase of the mission, to assess metrics upon which quantitative values of the impact of project products on decision-making can be compared. Key stakeholders from the EPA, NOAA, NRL, and NASA have expressed interest in PACE data for applications. We conducted an informal survey of the air quality applications community and found that they are inclined to use PACE aerosol products if these are produced and delivered to the community with specifications (resolution, latency, and format) similar to MODIS. Since systems to ingest and analyze MODIS products are already in place, the use of such PACE products will leverage existing infrastructure and expertise at very little cost.

\section{Conclusion}

PACE atmospheric measurements will provide the community with a unique dataset that will be exploited for air quality applications, beyond the science for which the instruments were designed. The spectral and spatial resolution of PACE measurements will meet current requirements for air quality applications, and will particularly be useful in coastal and urban areas with large gradients in air quality and for regions of the country where high-quality, real-time monitoring of air quality is currently lacking. The OCI and multiangle polarimeters on PACE will provide critical information about particle size, shape, and optical depth from which information about air mass characteristics can be inferred to inform policy on air quality, disaster mitigation, and hazard avoidance. In addition to augmenting and continuing NASA's satellite observations of aerosols and clouds, PACE products will address the large uncertainties of estimates of climate change parameters and the local weather responses to climate change relevant to applications for the insurance and reinsurance industry, and to policy makers, and protectors of the nation's infrastructure. A fairly robust plan to disseminate information to air quality managers and to attract and engage the air quality community through an EAs program has been developed. 


\section{References}

1. IPCC, Climate Change 2007: The Physical Basis. Contribution of Working Group I to the Fourth Assessment Report of the Intergovernmental Panel of Climate Change, p. 996, Cambridge University Press, Cambridge; New York (2007).

2. O. Boucher et al., Clouds and Aerosols Supplementary Material. Climate Change 2013: The Physical Science Basis. Contribution of Working Group I to the Fifth Assessment Report of the Intergovernmental Panel on Climate Change, Cambridge University Press, New York (2013).

3. National Research Council, Earth Science and Applications from Space: National Imperatives for the Next Decade and Beyond, p. 454, The National Academies Press, Washington, DC (2007).

4. National Academies of Sciences, Engineering, and Medicine, Thriving on Our Changing Planet: A Decadal Strategy for Earth Observation from Space, p. 700, The National Academies Press, Washington, DC (2018).

5. Y. J. Kaufman et al., "Operational remote sensing of tropospheric aerosol over land from EOS moderate resolution imaging spectroradiometer," J. Geophys. Res.: Atmos. 102(D14), 17051-17067 (1997).

6. P. F. Levelt et al., "Science objectives of the ozone monitoring instrument," IEEE Trans. Geosci. Remote Sens. 44(5), 1199-1208 (2006).

7. D. J. Diner et al., "Multi-angle imaging spectroradiometer (MISR) instrument description and experiment overview," IEEE Trans. Geosci. Remote Sens. 36(4), 1072-1087 (1998).

8. N. M. Foster, B. Cicin-Sain, and R. W. Knecht, Trends and Future Challenges for U.S. National Ocean and Coastal Policy August 1999, DIANE Publishing, Collingdale, Pennsylvania (1999).

9. https://pace.oceansciences.org/docs/pace_sdt_report_final.pdf.

10. O. M. Coddington et al., "Characterizing the information content of cloud thermodynamic phase retrievals from the notional PACE OCI shortwave reflectance measurements," J. Geophys. Res.: Atmos. 122(15), 8079-8100 (2017).

11. B. van Diedenhoven et al., "Remote sensing of ice crystal asymmetry parameter using multi-directional polarization measurements-part 2: application to the Research Scanning Polarimeter," Atmos. Chem. Phys. 13(6), 3185-3203 (2013).

12. http://airnow.gov/.

13. C. A. Pope, M. Ezzati, and D. W. Dockery, "Fine-particulate air pollution and life expectancy in the United States," N. Engl. J. Med. 360(4), 376-386 (2009).

14. A. Seaton et al., "Particulate air-pollution and acute health effects," Lancet 345(8943), 176-178 (1995).

15. Y. Liu et al., "Estimating fine particulate matter component concentrations and size distributions using satellite-retrieved fractional aerosol optical depth: part 2 - a case study," J. Air Waste Manag. Assoc. 57(11), 1360-1369 (2007).

16. A. van Donkelaar et al., "Global estimates of ambient fine particulate matter concentrations from satellite-based aerosol optical depth: development and application," Environ. Health Perspect. 118(6), 847-855 (2010).

17. B. L. Boys et al., "Fifteen-year global time series of satellite-derived fine particulate matter," Environ. Sci. Technol. 48(19), 11109-11118 (2014).

18. A. Ansmann et al., "Ash and fine-mode particle mass profiles from EARLINET-AERONET observations over central Europe after the eruptions of the Eyjafjallajökull volcano in 2010," J. Geophys. Res. 116, D00U02 (2011).

19. A. Stohl et al., "Determination of time- and height-resolved volcanic ash emissions and their use for quantitative ash dispersion modeling: the 2010 Eyjafjallajökull eruption," Atmos. Chem. Phys. 11(9), 4333-4351 (2011).

20. H. Flentje et al., "The Eyjafjallajokull eruption in April 2010-detection of volcanic plume using in-situ measurements, ozone sondes and lidar-ceilometer profiles," Atmos. Chem. Phys. 10(20), 10085-10092 (2010).

21. R. A. Kahn and J. Limbacher, "Eyjafjallajökull volcano plume particle-type characterization from space-based multi-angle imaging," Atmos. Chem. Phys. 12(20), 9459-9477 (2012). 
22. F. Marenco et al., "Airborne lidar observations of the 2010 Eyjafjallajökull volcanic ash plume," J. Geophys. Res.: Atmos. 116(D20), D00U05 (2011).

23. D. M. Winker et al., "CALIOP observations of the transport of ash from the Eyjafjallajökull volcano in April 2010," J. Geophys. Res. 117, D00U15 (2012).

24. R. A. Kahn, "Reducing the uncertainties in direct aerosol radiative forcing," Surv. Geophys. 33(3), 701-721 (2012).

Ali H. Omar, head of the Atmospheric Composition Branch at Langley Research Center, received his Ph.D. from the University of Illinois Urbana-Champaign (UIUC) in 1997. Ali did his postdoctoral fellowship at the UIUC Electro-Optics Systems Laboratory, working on the retrieval of temperature and aerosol profiles from NASA's Lidar In-space Technology Experiment (LITE) aboard space shuttle Discovery in September 1994. Ali is a science team member of the CALIPSO and PACE missions and led the CALIPSO aerosol classification algorithm development effort.

Biographies for the other authors are not available. 